East African Medical Joumal Vol. 78 No. 7 July 2001

EXPERIENCE WITH VINCRISTINE - ASSOCIATED NEUROTOXICITY*

N. A. Othieno-Abinya, MBChB, MMed, Departnent of Internal Medicine and L. O. Nyabaja, BSc, MSc, MPH, Department of Community Health, Faculty of Medicine. College of Health Sciences, University of Nairobi, P.O. Box 19676, Nairobi. Kenya.

Requests for reprints to: Dr. N. A. Othieno-Abinya, Faculty of Medicine, College of Health Sciences, University of Nairobi. P.O. Box I9676, Nairobi, Kenya

*This paper has been published in its abstract form in the Proceedings of the American Society of Clinical Oncology (ASCO) 36 th Annual meeting, New Orleans, LA, May 2000 , Abstr 846 .

\title{
EXPERIENCE WITH VINCRISTINE - ASSOCIATED NEUROTOXICITY
}

\section{N. A. OTHIENO-ABINYA and L. O. NYABOLA}

\begin{abstract}
Objectives: To evaluate the frequency and severity of occurrence of vincristine-associated neurotoxicity.

Design: A retrospective case series study

Setting: Hurlingham Oncology Clinic, Nairobi.

Subjects: Thirty-eight patients treated for various neoplasms with vincristine containing chemotherapeutic regimens.

Main outcome measures: The frequency and degree of neurotoxicity when vincristine was given at the standard dose of $1.4 \mathrm{mg} / \mathrm{m}^{2}$.

Results: Five patients $(13.2 \%)$ developed peripheral neuropathy, one having had it even before vincristine was started. Therefore only four $(10.5 \%)$ had it attributed to vincristine. Four of the patients who developed neuropathy $(80 \%)$ were HIV-positive. Neuropathy grade 2 (severe) occurred in only two patients leading to discontinuation of the drug. All the neurotoxicity resolved after discontinuation of vincristine.

Conclusion: Vincristine induced neuropathy occurred but was rarely severe at a dose of 1.4 $\mathrm{mg} / \mathrm{m}^{2}$. It appeared to be more frequent in HIV infected individuals, but controlled studies with bigger sample sizes are required to determine whether this may warrant routine capping of the dose at a maximum of $2 \mathrm{mg}$.
\end{abstract}

\section{INTRODUCTION}

Vincristine is one of the oldest cytotoxic agents in clinical use. It has a broad spectrum of anticancer activity, with a recommended dose of $1.4 \mathrm{mg} / \mathrm{m}^{2}$ administered intravenously. Administrations are repeated twice weekly or three weekly depending on the particular regimen employed. Peripheral neurotoxicity is the most frequent and dose-limiting toxicity of vincristine $(1,2)$. When used in combination with mustine hydrochloride, prednisone and procarbazine (MOPP) protocol used in the treatment of Hodgkin's lymphoma in its original description(3-5), high remission rates and long-term relapse-free survivals were realised. Howcver, when the dose is capped at the upper limit of $2 \mathrm{mg}$ as recommended by Moore $e t$ al at Stanford (6), relapse-free survival is attenuated as experienced by Bakemeier and colleagues of $\operatorname{ECOG}(7)$.

Vincristine is one of the cheapest of cytotoxic drugs, costing about 18 US Dollars per adult dose in Kenya on average. Its optimum use is therefore a matter of great oncologic importance, especially in economically disad vantaged settings. We routinely administer vincristine at full doses calculated at $1.4 \mathrm{mg} / \mathrm{m}^{2}$ to maintain the right dose-intensity, except in purely palliative treatments.

\section{MATERIALS AND METHODS}

A retrospect: analysis of data on patients treated with vincristine contain:ung regimens in our clinic between December 1992 and May 1999 was carried out. Details of age at commencement of treatment, sex, histology, evidence of human immunodeficiency virus (HIV) infection, treatment regimen employed, evidence of neurotoxicity, type of neurotoxicity, course of treatment at which neurotoxicity was first ex perienced, grade of neurotoxicity, treatment adjustment following neurotoxicity and neurotoxicity response to treatment discontinuation. From this information, cumulative dose of vincristine at which neurotoxicity was first recorded was derived. Peripheral neurotoxicity was graded according to World Health Organization (WHO) toxicity criteria (Grade 0 - none observed, grade 1 - paraesthesias and/or decreased tendon reftexes, grade 2-severe paraesthesias and/or mild weakness, grade 3-intolerable paraesthesias and/or marked motor loss, grade 4 -- paralysis). Fisher's exact test and the $Z$ test were used to compare neurotoxicity between HIV positive and negative cases.

\section{RESULTS}

Records were evaluated for a total of 38 patients; 25 males and 13 females. The age range was $16-72$ years, with a median age of 38 years. Sixteen patients tested positive for HIV infection while 22 were negative. Twenty- 
two patients had histologic diagnosis of malignant lymphomas, 12 had epidemic Kaposi's sarcoma, two soft tissue sarcomas, one multiple myeloma and one an anaplastic carcinoma. The median dose of vincristine per treatment was $2 \mathrm{mg}$ and the mean dose per treatment was $2.2 \mathrm{mg}$. The dose range per treatment was $2.0-2.8 \mathrm{mg}$.

Five patients $(13.2 \%)$ had documented peripheral neuropathy and their details are included in Table 1 . Their ages ranged between 16 and 45 years and the median age was 30 years. Of the se five patients one had neuropathy even before vincristine was started. She had been on zidovudine, didanosine and saquinavir. Only four ( $10.5 \%)$ had neuropathy attributable to vincristine. Two patients had neuropathy severe enough to have vincristine discontinued. A third patient had moderate neuropathy but demanded the discontinuation of vincristine after having been informed that it was most probably responsible for the symptoms. All cases of neurotoxicity resolved after discontinuation of vincristine even the case in whom it had been recorded before its initiation. limiting toxicity, occurs more frequently in patients who are older than 40 years and is related to cumulative dose. About $13.2 \%$ of our patients developed peripheral neurotoxicity though only $10.5 \%$ was attributed to vincristine. Because of the small sample size, no attempt was made to correlate occurrence of neuropathy with age. Eighty per-cent of our patients who developed neuropathy had HIV infection, a condition known to predispose to peripheral neurotoxicity(8). Various agents utilised in antiretroviral therapy are also known to be neurotoxic. Indeed one of the five patients who had neuropathy even before the administration of vineristine, was infected with HIV and was on antiretroviral therapy. This patient was treated for diffuse large B cell lymphoma. Lymphomas are also known to predispose to neuropathy associated with administration of vincristine. Severe forms of neuropathy such as convulsions and altered mental status that are also known to occasionally complicate vincristine administration were not observed(9).

Table 1

Peripherat neuropathy in relation to the warouts protocols

\begin{tabular}{|c|c|c|c|c|c|c|c|}
\hline Protocol & $\begin{array}{l}\text { No. of } \\
\text { patients }\end{array}$ & $\begin{array}{l}\text { No, with } \\
\text { neuropathy }\end{array}$ & $\begin{array}{c}\text { Vincristine course } \\
\text { at which neuropathy } \\
\text { occurred }\end{array}$ & $\begin{array}{c}\text { Grade of } \\
\text { neuropathy }\end{array}$ & $\begin{array}{l}\text { Vincristine } \\
\text { stopped? }\end{array}$ & $\begin{array}{l}\text { For neuropathy } \\
\text { cases, intercurrent } \\
\text { HIV infection }\end{array}$ & $\begin{array}{c}\text { For neuropathy } \\
\text { Vincristine dose } \\
\text { per treatment }\end{array}$ \\
\hline $\mathrm{COP}$ & 16 & 1 & 4 & Moderate & Yes & Yes & $2.6 \mathrm{mg}$ \\
\hline М-CHOP & 1 & 1 & 2 & Mild & No & No & $2.0 \mathrm{mg}$ \\
\hline$A B V$ & 5 & 1 & 3 & Severe & Yes & Yes & $2.0 \mathrm{mg}$ \\
\hline BV & 5 & 0 & - & - & - & - & $\ldots$ \\
\hline MACOP-B & 6 & $1 *$ & Severe at 2 & Severe & Yes & Yes & $2 \mathrm{mg}$ \\
\hline VAC & 2 & 0 & - & - & - & - & - \\
\hline BE-BVE & 1 & $1^{* * *}$ & $>20$ & Mild & No & Yes & $2 \mathrm{mg}$ \\
\hline Others & 2 & 0 & - & - & - & - & - \\
\hline
\end{tabular}

*Developed neuropathy even before vincristine was starled

**First had vincristine as a single agent many times.

CHOP - Cyclophosphamide, doxorubicin. vincristine, prednisone: M-CHOP - Methotrexate + CHOP: ABV - Doxorubicin, bleomycin, vincristine BV - Bleomycin, vincristine; MACOP-B - Methotexate, doxorubicin, cyclophosphamide, vincristine, prednisone, bleomycin: VAC - vincristine, doxorubicin, cyclophosphamide: BVE - Bleomycin, vincristine, etoposide

Four of the patients who had neuropathy $(80 \%)$ had tested positive for HIV infection. Only one out of $22 \mathrm{HIV}$ negative patients $(4.5 \%)$ developed neuropathy, but these differences were not statistically significant $(Z=1,841$. $P>0.05)$. Twenty-five per cent of HIV-positive patients developed neuropathy compared with only $4.5 \%$ of HIV negative patients. The difference was however not statistically significant $(P=0.09)$. The dose range per treatment was $2.2 \mathrm{mg}$. The cumulative dose at the time of vincristine associaled peripheral neurotoxicity ranged between 4 to $>40 \mathrm{mg}$.

\section{DISCUSSION}

Vincristine is virtually devoid of myelotoxicity, making it quite appropriate in combination chemotherapy. Peripheral neurotoxicity which is its most frequent dose
Routine capping of vincristine dose at a maximum of $2 \mathrm{mg}$ as recommended by the Stanford group because of fear of neurotoxicity results in a dose only suitable for persons smaller than $1.43 \mathrm{~m}^{2}$ and this has been shown to have deleterious effects on outcome $(6,10)$. A re-evaluation of full doses of vincristine regardless of body size was done in another study and confirmed the original NCI conclusion that use of full doses is feasible(11). Caution needs to be exercised when the drug is used in intensive weekly schedules such as previously adopted in combination with cyclophosphamide and prednisone (CVP)(12) which appeared to be more frequently associated with neurotoxicity (personal observations). None of our patients was treated with the weekly CVP combination. There are also antecedent neurologic disorders such as Charcot-Marie-Tooth disease, hereditary and sensory neuropathy type 1, and childhood poliomyelitis in which 
the use of vincristine should be discouraged $(13,14)$. None of our patients had any of these.

Vincristine-associated neurotoxicity occurs fairly frequently but appears to be rarely severe. The neuropathy tends to be more common in individuals infected with HIV. Whether this warrants routine capping of the dose of vincristine to a maximum of $2 \mathrm{mg}$ needs to be addressed in a prospective study with a large sample size.

\section{ACKNOWLEDGEMENTS}

To Susanne Mwongeta of Hurlingham Oncology Clinic for her excellent record keeping.

\section{REFERENCES}

1. Legha S.S. Vincristine neurotoxicity: Pathophysiology and management. Med. Toxicol. 1986: 1:421 - 427.

2. Tuxen M,K. and Hansen S.W. Neurotoxicity secondary to antineoplastic drugs. Cancer Treat Rev 1994: 20:191.

3. DeVita V.T. and Serpick A. Combination chemotherapy in the treatment of advanced Hodgkin's disease. Proc. Anter. Ass. Cancer Res 1967; 8:13.

4. DeVita V.T., Serpick A.A. and Carbone P.P. Combination chemotherapy in the treatment of advanced Hodgkin's disease. Ann Intern. Med 1970; 73:891-894.

5. Lowembraun S, DeVita V.T. and Serpick A.A. Combination chemotherapy with nitrogen mustard. vincrisitne, procarbazine and prednisone in previously treated patients with Hodgkin's disease. Blood. 1970; 36:704-717.

6. Moore M.E., Jones S. E. and Bull J. M. et. al. MOPP chemotherapy for advanced Hodgkin's disease: Prognostic factors in 81 patients. Cancer 1973; 32:52-60.

7. Bakemeier R.F., Anderson, J.R. and Castello W. et al . BCVPP chemotherapy for advanced E-Hodgkin's disease: Evidence for greater duration of complete remission, greater survival and less toxicity than with a MOPP regimen. Ann. Intern. Med. 1984; 101:447-456.

8. Navia B.A. and Price RW: Centraf and peripheral nervous system complications of AIDS. Clin. Immunol. Allergy. 1987; 6:543.

9. Rowinsky, E.K. and Donehower, R.C. The clinical pharmacology and use of antimicrotubule agents in cancer chemotherapeutics. Pharmacol. Ther. 1991; 14:115-119.

10. Carde, P., MacKintosh, R, and Rosenberg, S.A. A dose and time response analysis of the treatment of Hodgkin's disease with MOPP therapy. J. Clin. Oncol. 1983; 1:146-153.

11. Haim, N. et al. Full dose vincristine (without a $2 \mathrm{mg}$ dose limit) in the treatment of lymphomas. Cancer, 1994;15:2515.

12. Monfardini, S., Tancini, G. and Delena, N. etal. Cyclophosphamide, vincristine and prednisone (CVP) versus adriamycin. bleomycin and prednisone (ABP) in stage IV Non-Hodgkin's Lymphomas. Med. Paediat. Oncol. 1977; 3:67,

13. Griffiths, J.D., Stark, R.J., Ding, J.C. and Cooper, L.A. Vincristine neurotoxicity in Charcot-Marie-Tooth syndrome. Med. J. Aust. 1985; 143:305.

14. McGuire, S.A., Gospe, S.M., Jr. and Dahl, G. Acute vincristine neurotoxicity in the presence of hereditary motor and sensory neuropathy type 1. Med. Puediat. Oncol. 1989; 17;520. 